\title{
Internal Diameter Coating Processes for Bond Coat (HVOF) and Thermal Barrier Coating (APS) Systems
}

\author{
W. Tillmann ${ }^{1}$ C. Schaak ${ }^{1}$ L. Hagen ${ }^{1}$ G. Mauer $^{2}$ - G. Matthäus ${ }^{3}$
}

Submitted: 21 June 2018/in revised form: 19 October 2018/Published online: 30 October 2018

(C) ASM International 2018

\begin{abstract}
Current developments in different industrial sectors show an increasing demand of thermally sprayed internal diameter (ID) coatings. The most recent research and development is mainly focused on commercial applications such as arc spraying (AS), atmospheric plasma spraying (APS), and plasma transferred wire arc spraying, especially for cylinder liner surfaces. However, efficient HVOF torches are meanwhile available for ID applications as well, but in this field, there is still a lack of scientific research. Especially, the compact design of HVOF-ID and APS-ID spray guns, the need of finer powders, and the internal spray situation leads to new process effects and challenges, which have to be understood in order to achieve high-quality coating properties comparable to outer diameter coatings. Thus, in the present work, the focus is on the ID spraying of bond coats (BC) and thermal barrier coatings (TBC) for high-temperature applications. An HVOF-ID gun with a $\mathrm{N}_{2}$ injection was used to spray dense BCs (MCrAlY) coatings. The TBCs (YSZ) were sprayed by utilizing an APS-ID torch. Initially, flat steel samples were used as substrates. The morphology and properties of the sprayed ID coating systems were
\end{abstract}

This article is an invited paper selected from presentations at the 2018 International Thermal Spray Conference, held May 7-10, 2018, in Orlando, Florida, USA, and has been expanded from the original presentation.

C. Schaak

christopher.schaak@udo.edu

1 Institute of Materials Engineering, TU Dortmund University, Dortmund, Germany

2 Institute of Energy and Climate Research, IEK-1, Forschungszentrum Jülich GmbH, Jülich, Germany

3 Thermico GmbH \& Co KG, Dortmund, Germany investigated with respect to the combination of different HVOF and APS spray parameter sets. The results of the conducted experiments show that the HVOF-ID spray process with $\mathrm{N}_{2}$ injection allows to adjust the particle temperatures and speeds within a wide range. CoNiCrAlY bond coats with a porosity from 3.09 to $3.92 \%$ were produced. The spray distance was set to $53 \mathrm{~mm}$, which leads to a smallest coatable ID of $133 \mathrm{~mm}$. The porosity of the TBC ranged from 7.2 to $7.3 \%$. The spray distance for the APS-ID process was set to $70 \mathrm{~mm}$, which leads to a smallest coatable ID of $118 \mathrm{~mm}$.

Keywords bond coat $\cdot \mathrm{HVOF} \cdot$ internal diameter $\cdot$ particle speed $\cdot$ particle temperature $\cdot$ TBC

\section{Introduction}

\section{Internal Diameter Spraying (ID Spraying)}

The coating of rotationally symmetrical internal surfaces, e.g., the inside of a tube, can be realized with conventional spray guns up to a certain diameter and a certain depth of the part. With this method, the spray jet is directed on the internal surface at a normal angle or an off-angle as shown in Fig. 1, which is often referred to as "off-angle spraying" (Ref 1). Ideally, the spray angle during thermal spraying should be $90^{\circ}$. However, for "off-angle" spraying, it is impossible to stick to this basic rule of thermal spraying. It is well known that coating properties such as bond strength, porosity, roughness, hardness, and inherent stress depend on handling parameters such as the spray angle $(\operatorname{Ref} 2,3)$. By assuming a spray angle of an allowable maximum of $70^{\circ}$ and a theoretical spray distance of $300 \mathrm{~mm}$ (typical stand of distance range for outer diameter HVOF 


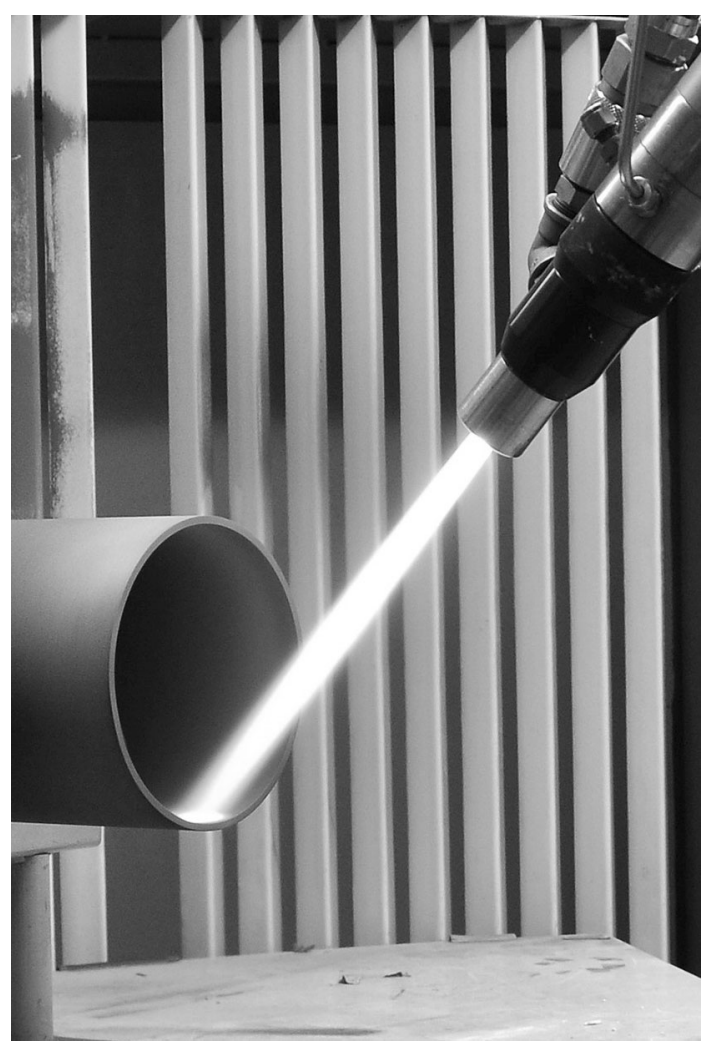

Fig. 1 Off-angle spraying of a tube (internal diameter $160 \mathrm{~mm}$ )

processes), results, by simple geometric calculations, a minimum coatable diameter of $d=281.9 \mathrm{~mm}$ with a coatable length of only $l=102.9 \mathrm{~mm}$ (compare Fig. 1). Otherwise the boundary condition of $70^{\circ}$ has to be exceeded. The mentioned process limits clearly limit the method "off-angle spraying".

The remedy is provided by special internal diameter spray guns or torches for internal diameter smaller $180 \mathrm{~mm}$ (Ref 4). These devices make it possible to coat even smaller internal diameters with a constant spraying angle, whereby the coatable length is significantly longer. To coat internal surfaces, thermal spraying processes such as arc wire spraying (AWS) and atmospheric plasma spraying (APS) or a combination of plasma transferred wire arc spraying (PTWA) and rotating single wire spraying (RSA) are scientifically investigated and are partly industrially established (Ref 5). In contrast, high-velocity oxygen flame spraying (HVOF) or high-velocity air flame spraying (HVAF) of internal diameters have hardly been considered scientifically so are also not well established in the industry.

\section{ID Spraying of BC and TBC}

Thermal barrier coatings (TBCs) are used as thermal insulations, oxidation and as corrosion protection for high- temperature applications. The durability of TBCs is influenced by delamination close to the interface between the ceramic topcoat and the BC. It is limited by the layer of thermally grown oxides (TGO), formed during service exposure. Hence, the $\mathrm{BC}$ plays an important role in the lifetime of a TBC. BCs can be applied by means of APS, HVOF or vacuum plasma spraying (VPS). VPS leads to ideal, dense, and microstructurally unique $\mathrm{BCs}$, but the process is expensive. HVOF processes also enable the production of $\mathrm{BCs}$ with a low porosity and comparable properties (e.g., oxygen content) (Ref 6). Furthermore, the bonding strength of the HVOF-sprayed BC is improved (Ref 6). The achieved microstructure and the physical properties of HVOF BCs strongly depend on the chosen spray process parameters (Ref 7,8 ). With adjusted spray parameters the pre-oxidation of the $\mathrm{BC}$ can be reduced (Ref 8). The particle size of the feedstock powder strongly influences the oxygen content of the BC (Ref 7). With finer particles $(5-37 \mu \mathrm{m})$ the oxygen content of the $\mathrm{BC}$ is higher than for coarser particles $(45-75 \mu \mathrm{m})$, due to the lower surface-area-to-volume ratio and the worse heating behavior (Ref 7). The comparison between HVOF and APS $\mathrm{BCs}$ showed that the aluminum content of HVOF BC is higher, because of a lower oxidation of the MCrAlY (Ref 11). This leads to a better TGO growth during high-temperature test (Ref 11). Because of these promising benefits, an increased number of researches on HVOF-sprayed BC is pursued (Ref 6-11). All conducted experiments are focused on the coating of external surfaces or outer diameters with conventional spray guns. Studies for HVOF BC spraying on internal diameters with specialized ID spray guns seem to be not yet available.

The feasibility of modern HVOF-ID systems for internal diameters as small as $160 \mathrm{~mm}$ [e.g., MJP-6000, Metallizing Equipment Co. PVT. LTD (Ref 12)], 125 mm [e.g., DJ Vortex ID, Oerlikon Metco AG (Ref 13)], $80 \mathrm{~mm}$ [SprayWerx Technologies (Ref 14)], or $63 \mathrm{~mm}$ [e.g., IDCoolFlow RED, Thermico GmbH \& Co KG (Ref 15)], opens the possibility for completely new applications. Next to wear protection by means of WC-CoCr or $\mathrm{Cr}_{3} \mathrm{C}_{2}-\mathrm{Ni} 20 \mathrm{Cr}$ coatings, $\mathrm{BCs}$ used for thermal barrier coatings on internal surfaces are future applications. To reach a high level of technology readiness, the first step is to analyze and understand the basic principles of ID spraying. HVOF-ID spraying already exposed some challenges compared to conventional HVOF external diameter spraying.

Most of these challenges are related to the compact design of HVOF-ID spray guns. The combustion chamber is smaller and the de Laval nozzle shorter when compared to conventional HVOF systems. Hence, the gas flow and combustion power are lower. In consequence, the spray plume length and diameter are smaller. The interaction of the temperature, speed, and the associated dwell time 
determine the melting and acceleration behavior of the spray particles. The combination of a short spray distance and a lower combustion power lead to the need of fine spherical spray powders $(d<20 \mu \mathrm{m})$ for HVOF-ID processes. These particles need less energy for melting and acceleration. Nevertheless, such fine spray powders show a bad flowability and thus are problematic for the use with most powder feeding systems. Additionally, the flow behavior of small particles in the flame differs from that of conventional powders. For example, fine powder particles tend to follow the gas flow trajectories better than larger particles (Ref 16). Due to the gas flow deviation near the surface of the substrate, the particles could be redirected and not impact on the surface. Furthermore, phenomena like the bow shock effect (Ref 17) could lead to a strongly reduced particle impact velocity and hence, a reduced deposition efficiency.

Another challenge is the high amount of heat energy that is transferred to the substrate and the corresponding cooling management. Special cooling methods like inside tube/bore cooling or small air-jet systems are necessary. Furthermore, the nozzle clogging and gun component degradation differ compared to outer diameter HVOF system. But these effects strongly depend on the spray parameters and the used spray powder feedstock.

APS-ID coating processes are also not commonly investigated. Some literature can be found for BC (Ref 18) and TBC (Ref 19) applications. The existing literature is, however, limited to basic experiments to find agreeable starting spray parameters.

In the present study, a HVOF-ID spray gun was used to apply a BC and an APS-ID gun was used to apply a TBC. In an initial step, the average particle velocity and temperature versus the spray distance were measured to gain information about the spray plume characteristics. The coating morphology was investigated for different parameters. The aim of the conducted experiments was to achieve a basic knowledge for the future development of these technologies.

\section{Experimental Details}

\section{Bond Coat Spraying (ID-HVOF)}

The BC was sprayed onto flat samples with the dimension $\varnothing 45 \times 5 \mathrm{~mm}$ made of C45 (1.0503 or AISI-1045) steel. The flat samples were used for morphology investigations. Prior to spraying, the substrate surface was grit blasted and cleaned in an ultrasonic bath. Additionally, the substrate was preheated to prevent thermally induced residual stresses.
For the BC coating process, a HVOF-ID gun (IDCoolFlow mono thermal spraying system with CPF2-Twin powder feeder, Thermico GmbH, Dortmund, Germany) was used. The IDCoolFlow mono gun is depicted in Fig. 2. The IDCoolFlow mono can be operated adding $\mathrm{N}_{2}$ to the combustion chamber. The $\mathrm{N}_{2}$ gas cools the combustion and increase the combustion chamber pressure. Hence, the gas flow speed was increased. Such processes are called warm spraying (Ref 20).

Three different spray parameter sets (SETI, SETII, SETIII) were applied for the experiments (Table 1). Based on the experience with the IDCoolFlow spray gun, the parameter sets should lead to differing flame temperatures and gas speeds.

SETI is a low thermal energy ("cold") parameter set with a high $\mathrm{N}_{2}$ injection into the combustion chamber and a lower kerosene rate. This procedure leads to a higher combustion chamber pressure, and thus, a higher gas speed rate (Ref 21). SETII and SETIII are "warmer" parameter sets. The spray angle is determined by the IDCoolFlow mono flame exit (compare Fig. 2). The spray distance was varied in the experiments.

A CoNiCrAlY Amdry 9951 (Oerlikon Metco AG, Wohlen, Switzerland) was used as spray feedstock. The particle size distribution is $-38 /+5.5$. The powder is gas atomized and spherical. For the HVOF-ID spray process, the powder size should be smaller than $20 \mu \mathrm{m}$. Hence, the powder was dry sieved with a mechanical shaker (Retsch $\mathrm{GmbH}$, Haan, Germany). After the sieving process, the particle size was measured with a S3500 (Microtrac, USA) laser diffraction system. The particle size distribution of the sieved powder is given in Fig. 3. The distribution shows a slightly bimodal shape. The arithmetic mean of the particle size is $9.45 \mu \mathrm{m}$ with a standard deviation of $4.38 \mu \mathrm{m}$. Thus, the particle size distribution is $d_{10}=4.48 \mu \mathrm{m}, d_{50}=7.59 \mu \mathrm{m}$, and $d_{90}=16.89 \mu \mathrm{m}$. The fine particle content with a diameter $<10 \mu \mathrm{m}$ is above $70 \%$. The particle size distribution seems to be slightly bimodal after sieving (Fig. 3).

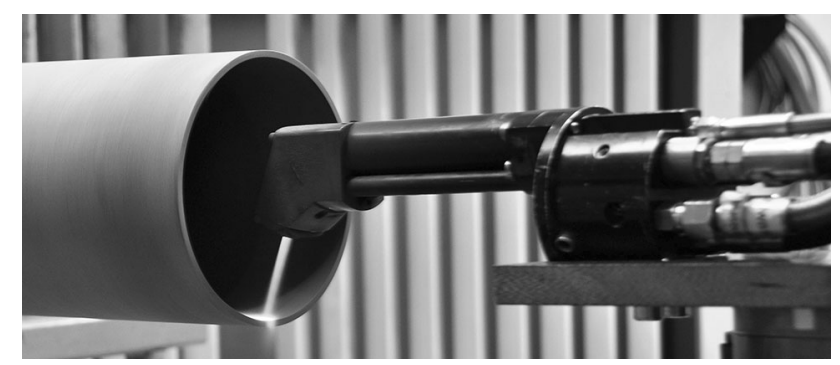

Fig. 2 IDCoolFlow Mono; ID spraying of a tube (internal diameter $160 \mathrm{~mm}$ ) 
Table 1 HVOF-ID spray parameter sets investigated for the BC application

\begin{tabular}{lllll}
\hline & SETI & SETII & SETIII & \\
\hline Nozzle length & 30 & 30 & 30 & $(\mathrm{~mm})$ \\
Hydrogen & 135 & 70 & 49 & $(1 / \mathrm{min})$ \\
Oxygen & 145 & 135 & 150 & $(1 / \mathrm{min})$ \\
Nitrogen & 100 & 15 & 0 & $(1 / \mathrm{min})$ \\
Kerosene & 2 & 3 & 3 & $(1 / \mathrm{h})$ \\
Powder feeder & CPF & CPF & CPF & \\
$\quad$ Carrier gas & 10.5 & 10.5 & 10.5 & $(1 / \mathrm{min})$ \\
$\quad$ Feed rate & 20 & 20 & 20 & $(1 / \mathrm{min})$ \\
$\quad$ Vibration pressure & 3 & 3 & 3 & $(\mathrm{bar})$ \\
Handling parameter & & & & \\
$\quad$ Spray distance & Variable & & & $(\mathrm{mm})$ \\
$\quad$ Spray angle & 70 & 70 & 70 & $\left({ }^{\circ}\right)$ \\
$\quad$ Track pitch & 2 & 2 & 2 & $(\mathrm{~mm})$ \\
$\quad$ Surface speed & 500 & 500 & 500 & $(\mathrm{~mm} / \mathrm{s})$ \\
\hline
\end{tabular}

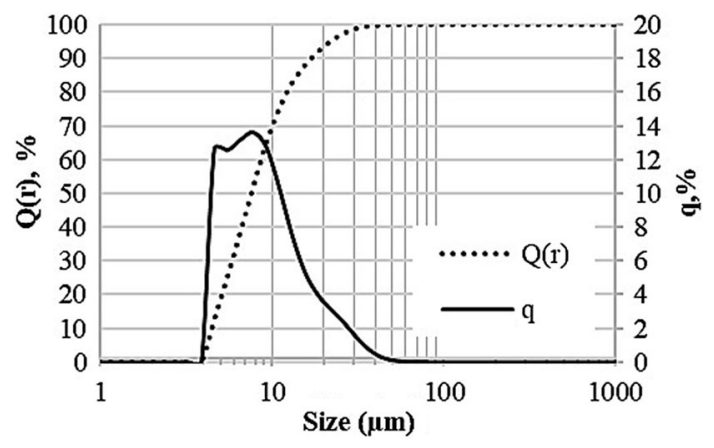

Fig. 3 Particle size distribution of the sieved $(<20 \mu \mathrm{m})$ AMDRY 9951 spray powder

\section{Thermal Barrier Coating Spraying (ID-APS)}

The ceramic topcoats were deposited onto the bond coated substrates without any pretreatment except a short cleaning in an ultrasonic bath. Atmospheric plasma spraying was performed in a Multicoat facility (Oerlikon (formerly Sulzer) Metco, Wohlen, Switzerland), applying a SM-F100 Connex ID-torch mounted on a six-axis robot. The feedstock was a commercially available, partially yttria-stabilized zirconia (7YSZ) HOSP $^{\mathrm{TM}}$ powder (Oerlikon Metco 204NS, $\left.d_{10}=28.2 \mu \mathrm{m}, d_{50}=54.4 \mu \mathrm{m}, \quad d_{90}=85.3 \mu \mathrm{m}\right)$ with a spherical morphology. The particle size distribution is listed in Fig. 4, and the spray parameters are listed in Table 2.

\section{Analysis Methods}

The temperature and the velocity of the HVOF-sprayed particles were measured in-flight with an Accuraspray-g3

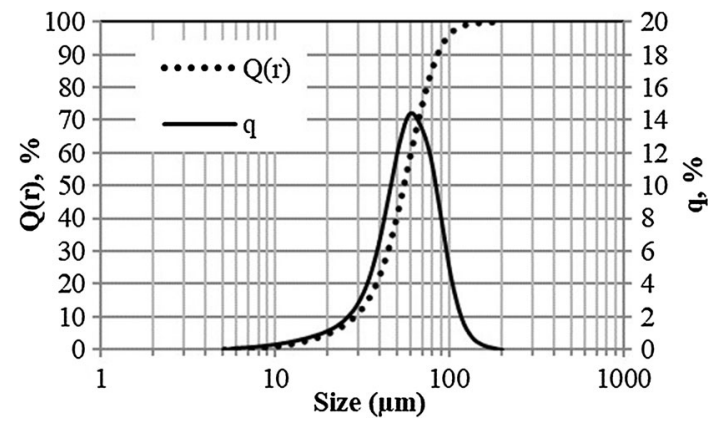

Fig. 4 Particle size distribution of the 7YSZ spray powder

Table 2 APS-ID spray parameter sets investigated for the TBC topcoat application

\begin{tabular}{lll}
\hline Argon & 30 & $(1 / \mathrm{min})$ \\
Hydrogen & 5 & $(1 / \mathrm{min})$ \\
Current & 380 & $(\mathrm{~A})$ \\
Powder feeder & Twin-120A & \\
$\quad$ Carrier gas & 2.5 & $(1 / \mathrm{min})$ \\
$\quad$ Feed rate & 27 & $(\mathrm{~g} / \mathrm{min})$ \\
Handling parameter & & \\
$\quad$ Spray distance & 70 & $(\mathrm{~mm})$ \\
$\quad$ Spray angle & 90 & $\left({ }^{\circ}\right)$ \\
$\quad$ Track pitch & 2 & $(\mathrm{~mm})$ \\
$\quad$ Surface speed & 500 & $(\mathrm{~mm} / \mathrm{s})$ \\
\hline
\end{tabular}

device (TECNAR Automation Ltd., St-Bruno, Qc, Canada). The measuring position was varied in $15 \mathrm{~mm}$ steps (standoff distance-SOD) from the spray gun torch to the end of the spray flame. The measuring frame was $1 \mathrm{~min}$ at each position. Particle in-flight diagnostics of the APS process were performed by means of the DPV-2000 system (TECNAR Automation Ltd., St-Bruno, Qc, Canada) and enables to measure the particle velocities, temperatures, and diameters (not applied in this work). The operating principles of both diagnostic systems are described elsewhere (Ref 22).

Cross-section images of the produced coating were taken by an optical microscope type Axiophot (Zeiss, Germany) and a FE-SEM with secondary-electron (SE) and backscattered electron (BSE) detectors type JSM-7001F (Jeol, Germany). The porosity was measured by means of digital image processing at the cross sections of the coating samples.

Vickers microhardness measurements were conducted along the cross section, using a microhardness tester type M-400 (LECO, Germany). The roughness values of the coating surface were measured with a tactile measurement machine (Hommel Tester T1000/TK300, Hommelwerke, Villingen-Schwenningen, Germany). 


\section{Results and Discussion}

\section{Bond Coat Spraying (ID-HVOF)}

As an initial step to investigate and understand the HVOFID spraying process of fine BC powder feedstock material, the particle temperature and velocity were measured inflight. The investigated starting parameter sets are based on the knowledge of applicable parameter sets for other fine spray powders (e.g., WC-Co(Cr)). The results of the particle in-flight measurements by means of Accuraspray-g3 are summarized in Fig. 5.

As expected, the particles sprayed with parameter SET I show the lowest particle in-flight temperature (Fig. 5a). The particle temperature ranges between 1200 and $1300{ }^{\circ} \mathrm{C}$ near the spray gun nozzle exit. The temperature decreases to values below $1000{ }^{\circ} \mathrm{C}$ at the end of the spray plume. Beyond this position (SOD $>90 \mathrm{~mm}$ ), the measurement of the particle temperature and speed was not possible, due to the low emission of the particles as the particles were too
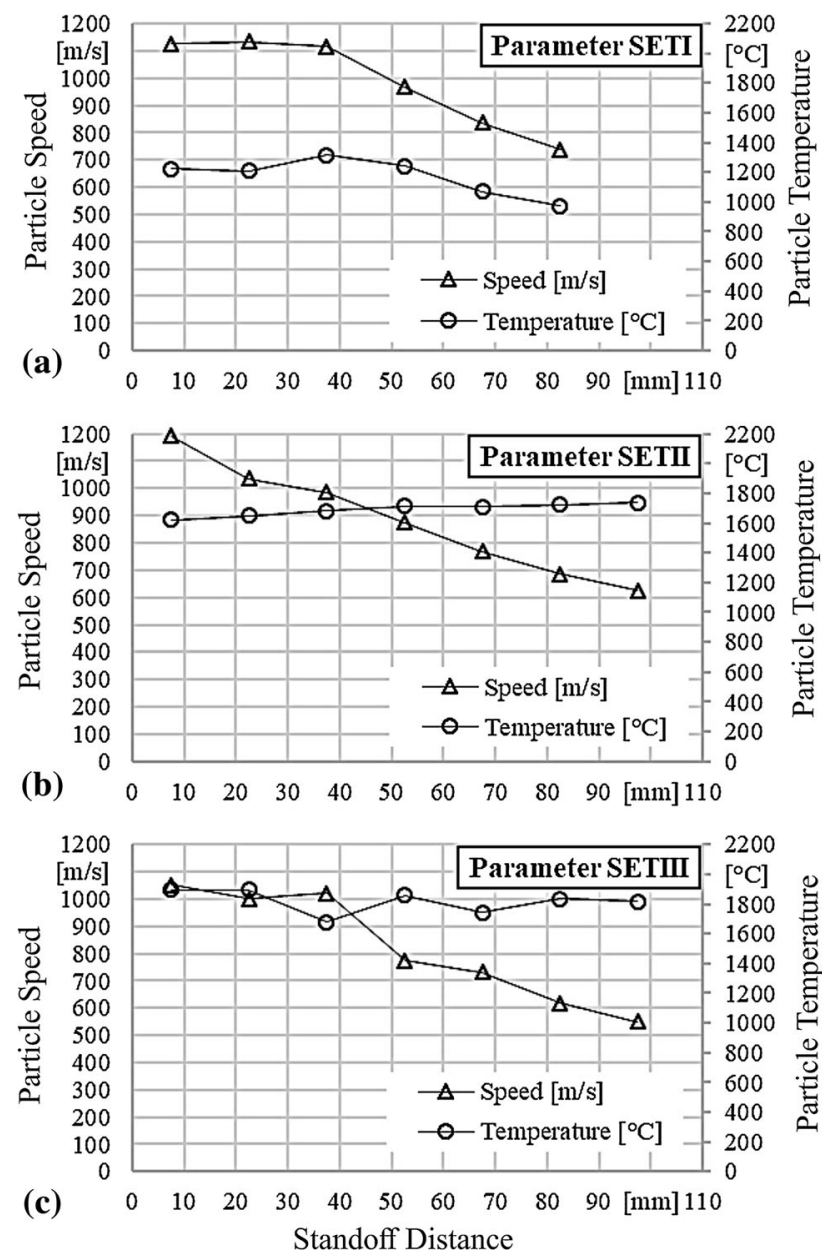

Fig. 5 Particle temperature and particle speed measured for parameter SET I (a), parameter SET II (b), and parameter SET III (c) at different spray distances (SOD) cold. The particle speed is very high and almost constant $(1115-1134 \mathrm{~m} / \mathrm{s})$ close to the nozzle exit and decreases with greater distances $(\mathrm{SOD}>50 \mathrm{~mm})$ from the nozzle exit.

The addition of $\mathrm{N}_{2}$ to the combustion leads to a higher gas mass flow into the combustion chamber, which directly leads to a higher pressure inside the combustion chamber. Furthermore, the inert $\mathrm{N}_{2}$ gas is heated by the combustion of $\mathrm{H}_{2}, \mathrm{O}_{2}$, and kerosene. This heat transfer leads to an expansion of the $\mathrm{N}_{2}$ gas and thus to a further increase of the combustion chamber pressure. Additionally, the combustion temperature decreased. This effect is visualized in Fig. 6. Higher $\mathrm{N}_{2}$ gas flow rates lead to a significant reduction of the particle in-flight temperature and to an increase of the particle speed. A particle speed of $1200 \mathrm{~m} / \mathrm{s}$ can be achieved with high $\mathrm{N}_{2}$ flow rates (for SETI: $\mathrm{N}_{2}$ : $125 \mathrm{l} / \mathrm{min}$ ) combined with low particle temperatures (circa $900{ }^{\circ} \mathrm{C}$ ). Such values are comparable to values of the cold spray process (Ref 23 ).

The particles sprayed with parameter SET II and SET III show a significantly higher in-flight temperature compared to SET I (see Fig. 5b/c). The particle temperature is almost constant for the measured SODs as well. For parameter SET II, the average particle temperature is $1690{ }^{\circ} \mathrm{C}$ and for SET III the average particle temperature is $1817^{\circ} \mathrm{C}$. The particle in-flight speed decreases for both parameter sets. In comparison, the measured particle speed is higher for the particles sprayed with parameter SET II. Directly at the nozzle exit, the in-flight particle speed for particles sprayed with parameter SET II is even higher when compared to parameter SET I.

Based on the presented results, only spray parameter SET I and SET III were chosen for coating spraying and morphology examination. The spray distance was set to $53 \mathrm{~mm}$ for both sets. With SET I, a BC with a high particle speed $(968 \mathrm{~m} / \mathrm{s})$ and moderate temperature $\left(1243{ }^{\circ} \mathrm{C}\right)$ at the moment of particle impact was sprayed. These coatings are compared to a $\mathrm{BC}$ that was sprayed with a high particle temperature $\left(1858^{\circ} \mathrm{C}\right)$ and moderate particle speed

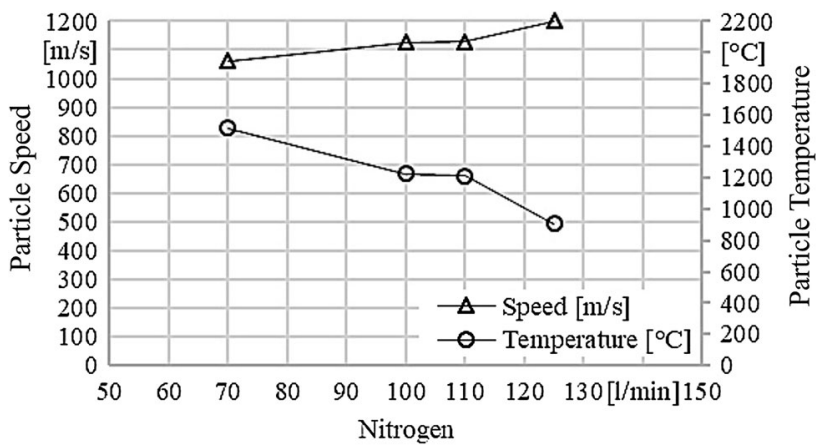

Fig. 6 Particle temperature and particle velocity, measured for parameter SET I with different $\mathrm{N}_{2}$ volume flow rates 
$(775 \mathrm{~m} / \mathrm{s})$, SET III. SEM images of the cross section of the produced coatings are shown in Fig. 7. Coatings sprayed with parameter SET III showed a delamination due to the mechanical preparation (see Fig. 7b), this could indicate a low adhesion of the coating.

The coating morphologies show a similar structure for both parameter sets (SET I and III). Coarser, un-melted particles are embedded in a matrix of fine splats of small, melted particles. This structure is especially visible in the BSE image (Fig. 7). The un-melted particles are partially deformed due to the impact energy.

The morphology has a familiar structure to cold sprayed (cold gas spraying) CoNiCrAlY (Ref 24, 25). Compared to HVOF and APS coatings, cold sprayed BCs have an improved high-temperature corrosion (oxidation) behavior (Ref 24, 25). In oxidation tests the HVOF BC fails after $5000 \mathrm{~h}$, a cold sprayed BC fails after $4300 \mathrm{~h}$, and an APS $\mathrm{BC}$ fails after $700 \mathrm{~h}$ (air atmosphere at $1050{ }^{\circ} \mathrm{C}$ ) (Ref 24). The reason for these results is the higher $\mathrm{Al}$ content of the CoNiCrAlY BC after spraying [APS: 9.6-17.9 at.\%; HVOF 14.7-23.2 at.\% (Ref 24)]. Furthermore, the oxide content after spraying is lower for HVOF $[0.75 \pm 0.23(\operatorname{Ref} 25)]$
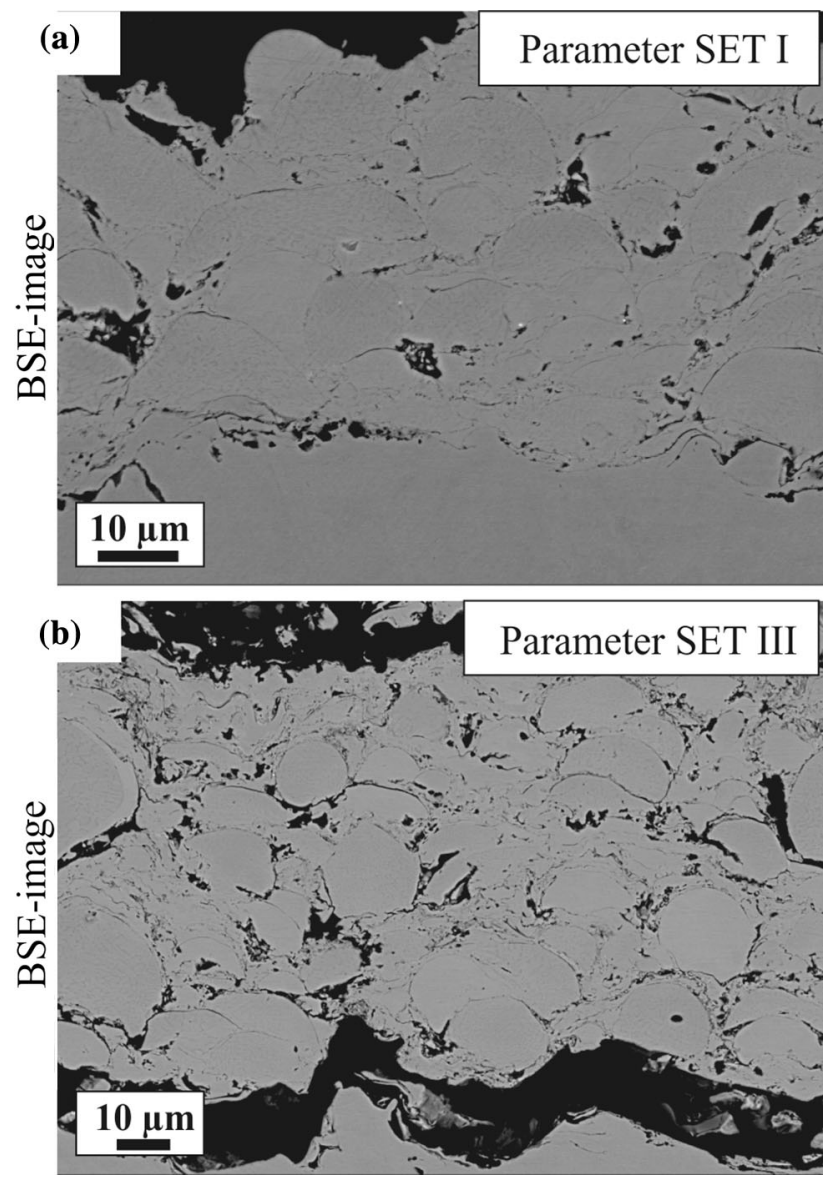

Fig. 7 Back-scattered electron (BSE) images of the HVOF BC (cross sections); (a) parameter SET I, (b) parameter SET III-spray distance: $53 \mathrm{~mm}$ than for APS $[3.82 \pm 0.70($ Ref 25)] sprayed CoNiCrAlY. In Ref 25 the HVOF-sprayed CoNiCrAlY BC shows the lowest mass gain after $100 \mathrm{~h}$ at $1000{ }^{\circ} \mathrm{C}$ (compared to APS and cold spray).

The average coating thickness for SET I is $56.3 \mu \mathrm{m}$ and the average porosity $3.9 \%$ The direct comparison of both coatings in Fig. 7 (SET I and SET III) reveal that parameter SET III leads to a higher coating thickness $(83.4 \mu \mathrm{m})$ and by trend lower average porosity $(3.09 \%)$, see Table 3 . Hence, both coatings were sprayed with 10 overruns, the deposition efficiency (DE) of SET III is by trend higher. The average hardness is slightly higher and the average roughness is slightly lower for the coating with SETI. Furthermore, the amount of splats (melted particles) is higher for SET III (Fig. 7b). The reason for the observed effects is the higher particle temperature reached with spray parameter SET III. In the present experiments, the achieved average porosity with the HVOF-ID system is higher than the porosity of CoNiCrAlY coatings produced by means of conventional HVOF $[0.5 \pm 0.1 \%$ (Ref 25)] and CGS $[1.0 \pm 0.3 \%$ (Ref 25)], but lower than APS $[5.3 \pm 0.5 \%$ (Ref 25)] CoNiCrAlY coatings (compared with Ref 25). Nevertheless, the standard deviation of the own measured porosity values is very high.

Nevertheless, the assumption can be made that the flame energy of the HVOF-ID system used was too low to melt the coarser CoNiCrAlY particles. Furthermore, only the surface temperature can be measured by means of the Accuraspray-g3 or DPV-2000 while information concerning the core temperature is missing. One explanation for this observation could be that only the small, melted particles were detected by the Accuraspray-g3 device or that the larger particles were not completely melted.

It is already known that the particle size should be smaller (ca. $d<20 \mu \mathrm{m}$ ) for HVOF-ID applications than for conventional HVOF systems (Ref 4, 13) due to the smaller spray gun size that leads to a lower combustion energy, combined with short spray distances. Furthermore, the powder feedstock should exhibit narrowly defined particle distribution sizes to ensure a uniform melting of the particles. Otherwise, effects like insufficient melting of particles and a high porosity, as shown in Fig. 7, could appear.

An observed problem was the spitting and nozzle clogging during longer coating times. Especially fine powders tend to spit during HVOF spraying (Ref 26). This problem will be taken into consideration in the future works.

\section{Thermal Barrier Coating Spraying (ID-APS)}

Similar to the BC production, initially particle diagnostic measurements were performed utilizing DPV-2000 to 
Table 3 Main quality values for the coatings sprayed with parameter SET I and SET III

\begin{tabular}{lcccr}
\hline & Hardness, HV 0.3 & Porosity, $\%$ & Thickness, $\mu \mathrm{m}$ & Ra, $\mu \mathrm{m}$ \\
\hline SET I & $370 \pm 16.6$ & $3.9 \pm 0.8$ & $56.3 \pm 6.4$ & $5.6 \pm 0.3$ \\
SET III & $325 \pm 21.3$ & $3.1 \pm 1.1$ & $83.4 \pm 5.2$ & $6.9 \pm 0.8$ \\
\hline
\end{tabular}

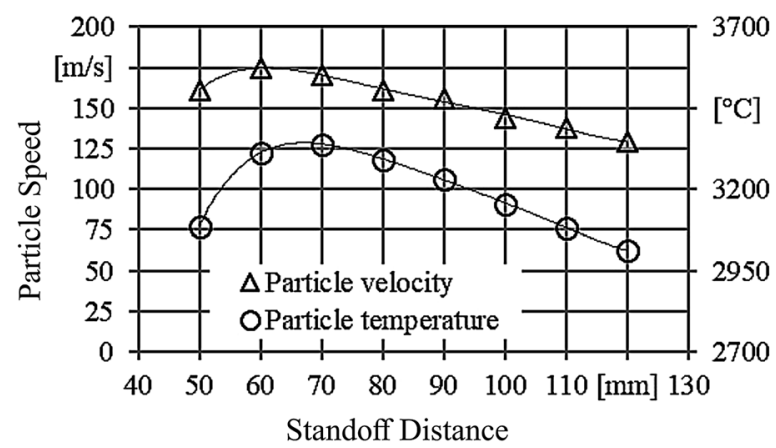

Fig. 8 Particle temperatures and particle velocities measured at different spray distances (SOD) for the APS YSZ deposition

identify suitable spray parameters and, in particular, to define the optimum spray distance. Figure 8 shows the results for a variation of the spray distance. One data point represents the average value of 5000 measured single particles.

Each measurement was focused on the plume center where the maximum particle numbers were triggered. Measurements were possible down to a distance of $50 \mathrm{~mm}$. Closer to the torch, the particle signals were blurred due to the superposition of the hot plasma core. Moreover, some vaporized feedstock material might have been present.

The particle temperatures are well above the melting point of YSZ and exhibit a maximum at $70 \mathrm{~mm}$. Here, the particle velocity is also almost at the maximum. Thus, this distance was selected for the subsequent spray experiments. These particle temperatures and velocities are in the typical ranges for YSZ depositions of TBCs by means of APS.

In contrast to the white YSZ feedstock powder, the deposited YSZ TBC was gray. This fact directly indicates a change of the valence states of zirconium [reduction of $\mathrm{ZrO}_{2}$ to $\mathrm{Zr}_{2} \mathrm{O}_{3}$ (Ref 27)] due to the thermal spray process. High energy spray parameters and the presence of a reducing plasma gas support this phenomenon (Ref 27).

Light microscope images of the cross sections of the produced $\mathrm{BC}$ and $\mathrm{TBC}$ double-layer systems are shown in Fig. 9. The main quality values of the TBC are summarized in Table 4. The average TBC thickness ranges between 336 and $352 \mu \mathrm{m}$. The average porosity was determined as $7.3 \%$, respectively, $7.2 \%$. The TBC properties' hardness, porosity, coating thickness, and roughness do not depend on the former $\mathrm{BC}$ properties in this case.

The microstructure of the deposited TBC coatings is characteristic for YSZ ceramic layers manufactured by APS (Fig. 10). The rapid solidification and shrinkage, combined with an obstructed contraction of the splats on

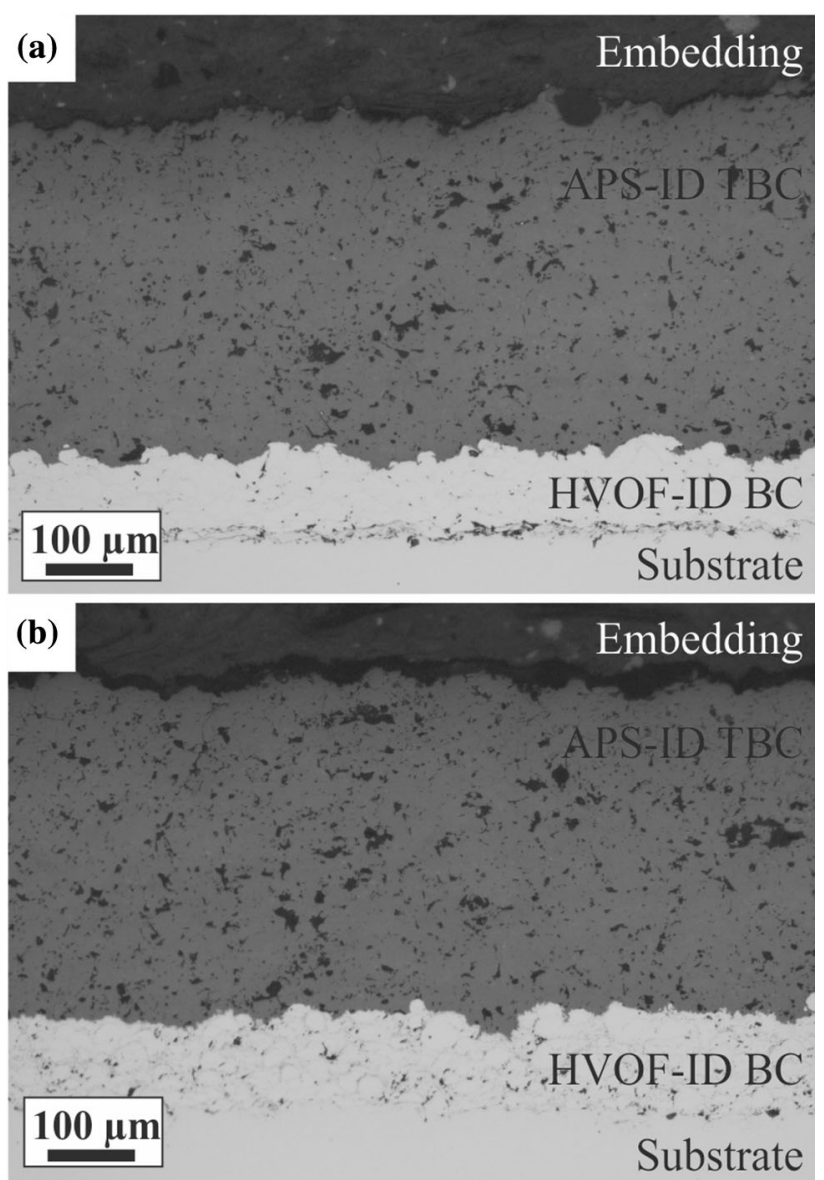

Fig. 9 Light microscope images of the HVOF-ID BC and APS-ID TBC double-layer systems (cross sections); (a) TBC on BC, sprayed with parameter SET I, (b) TBC on BC, sprayed with parameter SET III; (HVOF_-spray distance: $53 \mathrm{~mm}$; APS—spray distance: $70 \mathrm{~mm}$ )

the substrate or on the previously deposited layer, leads to tensile quenching stresses that are mainly relaxed by micro-cracking (Ref 28). This results in imperfections in the morphology such as a bad splat contact, inter-splat cracks, interlamellar cracks, and pores. The porosity is too low for TBC applications. Typical porosity values are in the range between cumulative 10-20\% (Ref 28) porosity. This could already be expected because of the measured high particle temperatures. Since the spray distance can hardly be increased, a lower plasma power will be applied for further works to achieve an adequate porosity.

The interface between the BC and the TBC shows a gapand pore-free interlocking (Fig. 11). The interface morphology is quite inhomogeneous with convex and concave fractions. This could lead to a non-uniform oxide growth 
Table 4 Main quality values for the TBC coatings, sprayed on the BC sprayed with parameter SET I and SET III

\begin{tabular}{lcccr}
\hline & Hardness, HV 0.3 & Porosity, $\%$ & Thickness, $\mu \mathrm{m}$ & Ra, $\mu \mathrm{m}$ \\
\hline TBC on SET I & $568 \pm 37$ & $7.3 \pm 0.9$ & $352 \pm 12.6$ & $6.7 \pm 0.4$ \\
TBC on SET III & $582 \pm 61$ & $7.2 \pm 0.9$ & $336 \pm 10.2$ & $6.8 \pm 0.1$ \\
\hline
\end{tabular}

three different spray parameter sets. $\mathrm{N}_{2}$ injection leads to a high particle speed combined with moderate particle temperatures. The morphology of the deposited HVOF-ID bond coats is similar to that of cold prayed CoNiCrAlY bond coats. The porosity of the produced coatings ranged from 3.09 to $3.92 \%$. Based on the chosen spray distance of $53 \mathrm{~mm}$ (HVOF-ID), the minimum coatable internal diameter is $133 \mathrm{~mm}$ (based on the IDCoolflow torch diameter of $80 \mathrm{~mm}$ ).

The particle characteristics of the APS-ID coatings were in the typical range of APS spray conditions, however, at high-temperature levels well above the melting point of YSZ. Consequently, a good adhesion and cohesion of the deposited structures can be expected. Besides, the porosity is still too low for TBC applications. This will be considered in future projects. Based on the chosen spray distance of $70 \mathrm{~mm}$ (APS-ID), the minimum coatable internal diameter is $118 \mathrm{~mm}$ (based on the SM-F100 torch diameter of $48 \mathrm{~mm}$ ).

The presented results show the high potential of modern ID spray systems. The combination of a small scale HVOFID and APS-ID spray torches opens the possibility to coat internal surfaces with adjusted BC/TBC systems.

\section{References}

1. A. Ghabchi, A. Thompson, and M. Froning, Off-Angle Thermal Spray Coating Deposition: Enabling Approach to Coat Small Internal Diameters, Boeing Co Briefing Charts, St Louis, 2012

2. U. Selvadurai, P. Hollingsworth, I. Baumann, B. Hussong, W. Tillmann, S. Rausch, and D. Biermann, Influence of the Handling Parameters on Residual Stresses of HVOF-Sprayed WC-12Co Coatings, Surf. Coat. Technol., 2015, 268, p 30-35

3. Š. Houdková, F. Zahálka, and M. Kašparová, The Influence of the Spraying Angle on Properties of Thermally Sprayed HVOF Cermet Coatings, Surf. Effects Contact Mech. IX, 2009, 62, p 5969

4. G. Matthäus, K. Bobzin, E. Lugscheider, and J. Zwick, Coating Properties of HVOF Sprayed Carbide-Based Ultrafine Powders, in Thermal Spray 2006: Science, Innovation, and Application, 2006, pp. 673-678

5. B. Krauß, Trend: Beschichtete zylinderlaufbahnen, VDI-Z Integrierte Produktion, Jun 2015.

6. C. Lima and J.M. Guilemany, Adhesion Improvements of Thermal Barrier Coatings with HVOF Thermally Sprayed Bond Coats, Surf. Coat. Technol., 2007, 201(8), p 4694-4701

7. B. Rajasekaran, G. Mauer, and R. Vaßen, Enhanced Characteristics of HVOF-Sprayed MCrAlY Bond Coats for TBC Applications, J. Therm. Spray Technol., 2011, 20(6), p 1209-1216

8. S.-W. Myoung, Z. Lu, Y.-G. Jung, B.-K. Jang, and U. Paik, Control of bond coat microstructure in HVOF process for thermal 
barrier coatings, in The 41st International Conference on Metallurgical Coatings and Thin Films, vol. 260(Supplement C), (2014), pp. 63-67.

9. H.-J. Jang, D.-H. Park, Y.-G. Jung, J.-C. Jang, S.-C. Choi, and U. Paik, Mechanical Characterization and Thermal Behavior of HVOF-Sprayed Bond Coat in Thermal Barrier Coatings (TBCs), Surf. Coat. Technol., 2006, 200(14), p 4355-4362

10. W.R. Chen, Degradation of a TBC with HVOF-CoNiCrAlY Bond Coat, J. Therm. Spray Technol., 2014, 23(5), p 876-884

11. W.R. Chen, X. Wu, B.R. Marple, D.R. Nagy, and P.C. Patnaik, TGO Growth Behaviour in TBCs with APS and HVOF Bond Coats, Surf. Coat. Technol., 2008, 202(12), p 2677-2683

12. Metallizing Equipment Co. PVT. LTD: MEC introduce gun for applying hard coating in internal dia. \& difficult to reach at area. MJP 6000. DOC\# MEC/MJP/-6000/2013.

13. J. Gutleber, R. Molz, J. He, C. Weber, and J. Colmenares, New developments in HVOF spraying for internal diameter coatings: Proceedings Internation, in Thermal Spray Conference, 2017, pp. 501-504.

14. A. Burgess, Novel HVOF torch for spraying internal diameters. Spraywerx Technologies, Inc., Canada, in Proceedings International Thermal Spraying Conference (ITSC), Düsseldorf, Germany, 2017, pp. 346-353.

15. Thermico $\mathrm{GmbH} \& \mathrm{Co}$. Kg: Innenbeschichtungen mit einem rotierenden. Brenner. http://thermico.de/DE/produkte/anlagen technik/brennertechnik/rmtu.html. 02 Oct 2018.

16. F.E. Marble, Dynamics of a gas containing small solid particles, in Combustion and Propulsion (5th AGARDograph Colloquium). Pergamon Press, New York, 1963, pp. 175-213. http://resolver. caltech.edu/CaltechAUTHORS:20110208-103139308

17. J. Pattison, S. Celotto, A. Khan, and W. O'Neill, Standoff Distance and Bow Shock Phenomena in the Cold Spray Process, Surf. Coat. Technol., 2008, 202(8), p 1443-1454

18. A. Léger, J. Wigren, and H. Hansson, Development of a Process Window for a NiCoCrAlY Plasma-Sprayed Coating, Surf. Coat. Technol., 1998, 108-109(Supplement C), p 86-92

19. M. Friis, C. Persson, and J. Wigren, Influence of Particle In-Flight Characteristics on the Microstructure of Atmospheric Plasma
Sprayed Yttria Stabilized $\mathrm{ZrO}_{2}$, Surf. Coat. Technol., 2001, 141(2), p 115-127

20. S. Kuroda, J. Kawakita, M. Watanabe, and H. Katanoda, Warm Spraying-A Novel Coating Process Based on High-Velocity Impact of Solid Particles, Sci. Technol. Adv. Mater., 2008, 9(3), p 33002

21. H. Haindl, Einfluß der Fertigungsparameter der Haftschicht auf die Lebensdauer keramischer Wärmedämmschichtsysteme, Herbert Utz Verlag Wissenschaft, Munich, 1998, ISBN 3-89675-3134

22. G. Mauer et al., Comparison and Applications of DPV-2000 and Accuraspray-g3 Diagnostic Systems, J. Therm. Spray Technol., 2007, 16(3), p 414-424

23. A. Moridi, M. Hassani-Gangaraj, M. Guagliano, and M. Dao, Cold Spray Coating: Review of Material Systems and Future Perspectives, Surf. Eng., 2014, 30, p 369-395

24. W.R. Chen, E. Irissou, X. Wu, J.-G. Legoux, and B. Marple, The Oxidation Behavior of TBC with Cold Spray CoNiCrAlY Bond Coat, J. Therm. Spray Technol., 2011, 20(1), p 132-138

25. P. Richer, M. Yandouzi, L. Beauvais, and B. Jodoin, Oxidation Behaviour of CoNiCrAlY Bond Coats Produced by Plasma, HVOF and Cold Gas Dynamic Spraying, Surface Coat. Technol., 2010, 204(24), p 3962-3974

26. S. Osawa, T. Itsukaichi, and R. Ahmed, Influence of powder size and strength on HVOF spraying - mapping the onset of spitting. Paper Presented at Advancing the Science and Applying the Technology, International Thermal Spray Conference, Florida, United States, 2003, pp. 819-824.

27. G.M. Ingo, Origin of Darkening in $8 \mathrm{wt} \%$ Yttria-Zirconia Plasma-Sprayed Thermal Barrier Coatings, J. Am. Ceram. Soc., 1991, 74(2), p 381-386

28. E. Bakan and R. Vaßen, Ceramic Top Coats of Plasma-Sprayed Thermal Barrier Coatings: Materials, Processes, and Properties, $J$. Therm. Spray Technol., 2017, 26(6), p 992-1010

29. A. Gil, V. Shemet et al., Effect of Surface Condition on the Oxidation Behaviour of MCrAlY Coatings, Surf. Coat. Technol., 2006, 201(7), p 3824-3828 